\title{
PEDRA SOBRE PEDRA: TERRA, TRABALHO E CONSCIEENCIA NA PERSPECTIVA LITERÁRIA-MUNDIAL
}

STONE UPON STONE: LAND, LABOUR AND CONSCIOUSNESS IN WORLD-LITERARY PERSPECTIVE

Neil Lazarus

Via Atlântica, São Paulo, n. 40, p. 13-72, nov. 2021.

doi: 10.11606/va.i40.173466 
Resumo: A história de um(a) jovem que vem das províncias à cidade em busca de trabalho - este é um dos topoi centrais da ficção moderna. Romance após romance, vemos a força centrípeta da cidade. A transformação incessante, irregular e incessante da cidade por meio da modernização é então sobre determinada nessas narrativas literárias de campo a cidade por ser representada sob o signo do choque do novo, à medida que os protagonistas rurais são levados a confrontar seu ritmo, tamanho, intensidade, aspereza e insensível impessoalidade. A cidade é evidentemente o locus dominante de modernização no sistema-mundo capitalista, em contrapartida, com muito menos representação, o campo, menos presente, é representado como matriz esgotada, cada vez menos capaz de sustentar a vida, não apenas afetiva ou experiencialmente, mas também muitas vezes literariamente.

Palavra-chave: literatura-mundial; literatura comparada; teoria literária. 
Abstract: The story of a young man (or woman) who comes from the provinces to the city to look for work - this is one of the central topoi of modern fiction. In novel after novel, we are shown the centripetal force of the city. The city's restless, jagged and unceasing transformation through modernization is then overdetermined in these country-to-city literary narratives through being represented under the sign of the shock of the new, as the rural protagonists are made to confront its pace, size, intensity, abruptness, and callous impersonality. The city is so transparently the dominant locus of modernization in the capitalist world-system, in contrast, the countryside is represented as a depleted matrix, less and less capable of sustaining life, not only affectively or experientially, but also often literally.

Keyword: world-literature; comparative literature; literary theory. 
Alguns dos escritos mais comoventes e consequentes da era moderna se dedicaram, adequadamente, à tarefa de descrever as vidas daqueles que ficam para trás na fazenda e na aldeia quando tantos de sua coorte - companheiros da aldeia, vizinhos, amigos, familiares - saem para procurar trabalho na cidade. Pode-se pensar na trilogia de John Berger, Into their Labors, que trata da experiência do campesinato alpino ao longo do século XX; ou o grande romance de Wiesław Myśliwski, Stone upon stone; ou a obra do islandês Halldór Laxness, do sueco Vilhelm Moberg, do espanhol Ramón J. Sender, dos russos Grigorovich, Turgenev, Chekhov, Tolstoy, Leskov; e assim por diante.

Em meu artigo, tentarei colocar esta classe de escrita em contraponto com o trabalho "pós-colonial", cujas condições de habilitação são às vezes análogas, e às vezes bastante diferentes. Será necessário pensar um pouco sobre duas questões em particular. A primeira delas diz respeito à concepção popular dominante da vida rural como estando de alguma forma fora, além ou abaixo da história moderna, deixada para trás pelas forças da modernização e existindo no mundo contemporâneo apenas como uma espécie de relíquia - inalterada e imutável, do mesmo jeito que sempre esteve e, por isso mesmo, à beira da extinção em um ambiente social capitalista marcado pela 
"constante revolução da produção, perturbação ininterrupta de todas as condições sociais, [e] incerteza e agitação eternas". A segunda diz respeito ao problema da representação: nas obras literárias que tratam da vida rural, e especialmente do campesinato, qual é a visão de classe da narração? Qual é a relação entre a voz falada (e a ideologia ou consciência social que a governa) e os personagens, práticas sociais, ideias e convenções faladas ou expressas? Como podemos levar essas questões em consideração em nossa leitura das obras literárias que nos interessam?

O narrador sem nome do romance de Knut Hamsun de 1890, Hunger, é um jovem que vem das províncias para Kristiania (atual Oslo) para tentar ganhar a vida como escritor. A fome mapeia a crescente miséria e desespero de seu protagonista enquanto ele luta - e não consegue encontrar - trabalho, abrigo e sustento. Sua ambição criativa é progressivamente eliminada; ele fica reduzido a esperar apenas que seja capaz de vender o que escreve, de transformar o que produz em dinheiro para poder comprar comida. Em uma passagem típica, nós o encontramos acordando muito cedo cheio de ideias na cabeça. Seu estado de alerta é meio delírio. Ele não come nada há dias e não faz uma refeição adequada há semanas. Ele pega um lápis e começa a escrever. Excepcionalmente, as palavras fluem. Uma estranha felicidade o invade. Mas 
o que é surpreendente é que essa "felicidade" mal foi registrada, já é descrita como mediada pelo valor de troca. 0 que ele escreve assume para ele a forma de bens vendáveis, cuja medida "natural" é monetária:

Os pensamentos fluíram tão abruptamente, e continuaram vindo em tal fluxo, que perdi alguns deles por não ser capaz de escrevê-los rápido o suficiente, embora trabalhasse com toda a minha energia. Eles continuaram a se pressionar contra mim; Eu estava profundamente envolvido e cada palavra que escrevi vinha de outro lugar... Fiquei tonto de contentamento, a alegria cresceu em mim, me senti magnífico. Pesei a peça em minha mão e avaliei no local com uma estimativa aproximada de cinco coroas. Ninguém jamais barganharia cerca de cinco coroas por isso. Pelo contrário. Em vista da qualidade, pode-se chamar de puro roubo obter a peça por dez. A última coisa que eu tinha em mente era fazer um trabalho tão notável de graça; minha experiência é que não se encontram histórias desse tipo espalhadas pela rua! Eu decidi definitivamente por dez coroas (Hamsun, p. 48).

Hunger é angustiante e inquietante: quanto mais a narrativa avança, mais desesperada se torna a busca turbulenta e desoladora do protagonista por algo - qualquer coisa - para comer. Ele é reduzido em um 
ponto a tentar comer uma lasca de madeira; em outro, a mastigar um bolso que rasgou de sua própria jaqueta; em outro, ainda, a chupar uma pedra. Ele passa de uma condição em que sente fome ("meramente" com fome, por assim dizer) para uma em que sabe que está morrendo de fome e morrerá se não encontrar algo para comer em breve. A fome tira sua dignidade, julgamento, integridade e ser social. Segundo Robert Ferguson, o que somos confrontados aqui não é a consciência corporificada (Ferguson, p. 112). Pelo contrário, na medida em que o narrador retém qualquer sentido de si mesmo sob a coação extrema a que está exposto, não é como um sujeito que ele conhece a si mesmo, mas apenas como um corpo recalcitrante e totalmente objetivo em necessidade.

A recepção crítica de Hunger tende a vê-lo como uma "porta" para o modernismo internacional. A tendência, como explica Timothy Wientzen, tem sido abstrair do fato de que o narrador está literalmente morrendo de fome e interpretar sua fome metaforicamente como o desejo de reconhecimento ou autorrealização no contexto abrangente de uma luta existencial pela autenticidade. Nessa interpretação convencional, o experimentalismo do romance - seu subjetivismo radical, por exemplo, sua busca do narrador até a loucura e desordem - é assimilado aos registros modernistas paradigmáticos de 
alienação, angústia e anomia, e a própria obra situada como "uma exemplo de estética modernista" (Wientzen, p. 208). Wientzen nos remete ao ensaio emblemático de Paul Auster de 1970, 'The Art of Hunger', que compara a obra de Hamsun à parábola de Franz Kafka, 'A Hunger Artist', e a lê como um romance 'sobre a experiência universal da modernidade urbana e seu ataque concomitante na psique, um romance nos moldes de Mrs. Dalloway or Ulysses' (qtd. Wientzen, p. 210). $^{1}$

O próprio Wientzen questiona esta linha de interpretação, cujo "internacionalismo" bajula apenas para enganar. Longe de lançar luz sobre a fonte da imaginação de Hamsun, Wientzen argumenta, o alardeado comparativismo literário dos teóricos do modernismo "internacional" prova ser profundamente descontextualizante. Mas Wientzen não pede um recuo metodológico para o particular incomensurável - o texto de Hamsun dificilmente é tão específico para seu próprio tempo e lugar a ponto de ser incomparável com outros escritos de outras épocas ou lugares - propondo, em vez disso, um comparativismo literário mais rigoroso e bem fundamentado. É apenas quando pensamos sobre Hunger em relação à categoria sociológica do sistema-mundo moderno que as características formais particulares da obra - sua

\footnotetext{
${ }^{1} \mathrm{O}$ artigo de Auster foi reimpresso em The Art of Hunger, de onde Wientzen extrai suas citações.
} 
estrutura estética única e lógica interna - se tornam totalmente compreensíveis:

À medida que as nações que entravam em uma economia mundial emergente, elas encontravam níveis historicamente sem precedentes de insegurança nutricional e fome. 0 corpo faminto tornou-se um elemento-chave nos projetos modernistas... Embora raramente pensemos na Noruega como posicionada às margens do desenvolvimento capitalista... [estava] entre os países menos desenvolvidos da Europa no século XIX, uma realidade que esteve no trabalho de alguns dos primeiros pintores e escritores do modernismo. Em Hunger..., Hamsun invocou uma história de desenvolvimento econômico que dotou o corpo faminto de um significado transnacional. Repetindo a própria abordagem do romance naturalista à fome, Hunger reflete a reconfiguração transnacional das formas econômicas, que dependiam centralmente do aproveitamento das necessidades corporais de populações inteiras para fins produtivos (Wientzen, p. 209)

O projeto formal de Hamsun em Hunger, então, toma forma como um registro da relativa perifericidade da Noruega no sistema-mundo no momento da composição da obra. Em outras palavras, isso é menos "modernismo internacional" do que "modernismo do subdesenvolvimento" - para usar o termo 
desenvolvido por Marshall Berman em seu grande estudo da experiência da modernidade. Lembremos também neste contexto a defesa de Fredric Jameson de um novo tipo de bolsa literária comparativa, que envolveria a 'comparação, não dos textos individuais, que são formal e culturalmente muito diferentes uns dos outros, mas das situações concretas das quais tais textos surgem e para os quais constituem respostas distintas' (Third-World Literature, p. 86-87). Para aqueles de nós que, como eu, tende a pensar esquematicamente, esta conceituação dá origem à tentação de conjurar uma contra-lista de obras literárias "modernistas", para colocar ao lado da lista a que os críticos "modernistas internacionais" costumam nos referir. Portanto, no que diz respeito a Hamsun (e a Hunger, o romance, assim como à fome (hunger) a difícil situação), não Joyce, Virginia Woolf, Kafka, etc. - ou, pelo menos não apenas eles, ou eles não nessa mesma forma mas (digamos, Velimir Khlebnikov, Kang Kyŏng-ae, Liam O'Flaherty, Bhabani Bhattacharya, Martin Carter, Kamala Markandaya, Antônio Torres, Dambudzo Marechera, Mohamed El-Bisatie, Liu Zhenyun, Alli Ollikainen... ${ }^{2}$ To-

${ }^{2}$ As obras que estou pensando aqui são: Velimir Khlebnikov, 'Hunger' [1921]; Kang Kyŏng-ae, From Wonso Pond [1934]; Liam O’Flaherty, Famine [1937]; Bhabani Bhattacharya, So Many Hungers! [1947]; Martin Carter, 'University of Hunger' [1954]; Kamala Markandaya, Nectar in a Sieve [1954]; Antônio Torres, The Land [1976]; Dambudzo Marechera, The House of Hunger [1978]; Mohamed El-Bisatie. Hunger: An Egyptian Novel [2008]; Liu Zhenyun, Remembering 1942 and other Chinese Stories [2009]; Aki Ollikainen, White Hunger [2012]. 
dos esses são autores de obras identificáveis "modernistas" que lutam centralmente com a miséria, fome ou falta de alimentos socialmente engendradas e cujo experimentalismo formal, muitas vezes mal compreendido e menosprezado em seu próprio momento, torna-se totalmente inteligível apenas quando é compreendido por uma metodologia comparativa sensível à 'situação concreta', bem como 'resposta [literária] distinta', isto é, tanto ao 'mundo' como ao 'trabalho'.

Há uma passagem impressionante em The Beautyful Ones Are Not Yet Born, de Ayi Kwei Armah, em que o protagonista (que não tem nome, como no romance de Hamsun) deixa o Escritório de Controle de Tráfego em que trabalha no horário de almoço e caminha, seguindo os trilhos do trem, para o porto. Ele está com muita fome, mas não tem comida. Seu salário é insuficiente para manter sua família semana após semana e, portanto, sua vida é apertada e miserável. 0 romance fala do 'ciclo médio mensal de endividamento e empréstimo, empréstimo e endividamento': para o protagonista e muitos ganenses cujas circunstâncias materiais são semelhantes às dele, 'a hora do almoço não era um momento para se refrescar'. Ele caminha para evitar que sua mente pense em como ele está com fome. No início, seus pensamentos são atraídos para a infelicidade irremediável de sua vida, 
mas de repente sua recusa desesperada de se permitir ser definido por sua fome - por mais sombria que seja sua situação, afinal não é tão ruim quanto a do protagonista de Hamsun - emerge uma estranha sensação de lucidez e resolução:

[0] homem seguiu a linha dos trilhos de aço duro onde eles se curvavam para fora e para longe de dentro do pátio da locomotiva e se endireitavam à frente para o impulso penetrante e melancólico no interior do país. No leito de cascalho sob o metal, a mistura de cinzas caídas e pedaços perdidos de carvão de motor e graxa vaporizada levantou em algum lugar na região de sua garganta o fedor quente do desespero e a derrota de uma cozinha doméstica já bem usada, toda a sua atmosfera feita de línguas da fumaça humilhante de todos aqueles dias de ontem. À frente, no entanto, os rastros seguiam em linha reta e brilhante e o ar acima do aço balançava com o poder do sol até que todas as coisas da tarde vistas através do ar pareciam fluidas e não mais sólidas. 0 azedume que vinha se formando em sua boca sumiu imperceptivelmente até que, de repente, tudo que ele percebeu foi a clareza de visão extremamente nítida e o sabor limpo que vem com o sucesso do combate à fome (Armah, p. 21-22) 
0 mundo pós-colonial denotado aqui, e em todo o romance, é definido não por sua falta de desenvolvimento, mas por seu subdesenvolvimento abrangente. Por um lado, temos os leitos de cascalho, metal, carvão para motores, graxa e trilhos de aço brilhante; de outro, no perímetro do pátio da locomotiva, as pequenas parcelas de terra árida em que trabalhadores migrantes do norte do país - Tamale, digamos, ou Yendi - agora tentam crescer o suficiente para se manterem vivos. Penetrando profundamente no interior do país, a rede ferroviária indica uma espécie de modernização; no entanto, essa modernização foi planejada e construída não para facilitar o comércio e a comunicação entre o próprio povo de Gana, mas para transportar mercadorias - bauxita, minério de ferro, cacau - dos pontos do interior em que são cultivadas ou mineradas até os portos no sul, de onde podem ser despachados para destinos nas zonas capitalistas centrais, sujeitos a uma lógica político-econômica que Armah entende como neocolonial. A integração de Gana no sistema econômico mundial ocorreu às custas do bem-estar social de seu povo. 'Tanto tempo se passou e ainda não há doçura aqui' (Armah, p. 67) ${ }^{3}$. A independência política pode ter

${ }^{3}$ Armah pega emprestada a frase "sem doçura aqui" de um conto escrito por sua compatriota e amiga Ama Ata Aidoo. A história de Aidoo foi publicada pela primeira vez em 1964, mas reimpressa como a história-título em sua coleção, No Sweetness Here [1970]. Ela discute sua amizade literária com Armah em 'To Be an African Woman Writer'. 
chegado a Gana, mas o pouco crescimento que existe no mundo do romance é apenas quantitativo, seus frutos zelosamente acumulados por uma elite cleptocrática e comprados à custa da estagnação qualitativa ou, pior, do enfraquecimento ou mesmo destruição, da sociedade em geral.

Estilisticamente, a passagem é notável por encenar uma "desconexão" entre a palavra e o mundo. A linguagem (tom, léxico, registro) que Armah usa para descrever a realidade encontrada por seu protagonista é compacta, densa, quase enjoativa. A passagem não é fácil de ler em voz alta. As frases são longas, intrincadas, adjetivamente saturadas e entrópicas: "caído ... perdido ... vapor ... superaquecido ... fingido ... humilhante". Somos levados a compreender que a realidade vivida pelo protagonista (o romance se refere a ele apenas como "o homem") é tão implacável e derrotante que ameaça até mesmo os aspectos comunicativos e intersubjetivos da linguagem. Também nesta dimensão - como nas dimensões mais solidamente materiais da produção e reprodução social - apenas um frágil e negativo fio dialético liga o presente degradado aos "belos" do futuro longo. A linguagem pode manter a fé na ideia de comunidade apenas se distanciando conscientemente do discurso 
público, que foi contaminado pela lógica social dominante e agora é inutilizável. ${ }^{4}$

Os primeiros leitores do romance de Armah não conseguiram entender tudo isso. 0 padrão que Wientzen notou na recepção de Hunger de Hamsun também foi evidente na recepção inicial de The Beautyful Ones Are Not Yet Born. Mas no contexto literário africano do final dos anos 1960, preocupado acima de tudo com o projeto de descolonização cultural, uma oposição severa e redutiva foi muitas vezes operacionalizada entre os discursos literários 'Afrocêntrico' e 'Eurocêntrico', e o romance de Armah foi lido nos termos de esta oposição contundente. Se a tendência da recepção crítica de Hunger tem sido de celebrar a obra como "um dos primeiros exemplos da estética modernista", então, mutatis mutandis, a tendência da recepção crítica inicial de The Beautyful Ones foi de deplorá-la, como um exemplo tardio dessa mesma estética modernista - só agora vista como provinciana e chauvinisticamente "europeia" em impulso e proveniência, em vez de "internacional" (ou "uni-

${ }^{4}$ Dentro do romance, a lógica social predominante é representada por meio da metáfora estendida do "brilho". Para comentários sobre o uso do conceito de 'brilho' por Armah em The Beautyful Ones, veja minha obra Resistance in Postcolonial African Fiction [1990]. Consulte também 'Excremental Postcolonialism' [1999] de Joshua Esty, e 'Pessimism, Autonomy, and Commodity Fetishism in Ayi Kwei Armah's The Beautyful Ones Are Not Yet Born' [2003] de John Lutz. 
versal"): Daí a acusação de "Euro-modernismo" que muitas vezes foi lançada contra escritores africanos como Armah, Wole Soyinka, Christopher Okigbo e Kofi Awoonor. Em sua crítica massivamente influente do romance de Armah, por exemplo, Chinua Achebe escreveu que embora fosse "um livro bem escrito" "O domínio da linguagem e imagens de Armah é de fato de um nível muito elevado" - não importava e o livro continuava sendo 'um livro doentio':

Doente, não com a doença de Gana, mas com a doença da condição humana. 0 herói, pálido e passivo e sem nome - uma criação na melhor maneira da escrita existencialista - vagueia pela história em um meio-sono angustiado, mergulhado em desespero e excremento humano do qual vemos bastante no livro. Eu disse que ele se recusou a ser corrompido? Ele não fez nada tão positivo quanto recusar. Ele me lembrava fortemente aquele homem e mulher em um romance de Jean-Paul Sartre que se sentam em uma tristeza angustiada em um restaurante e então, em um súbito excesso de energia niilista, agarram facas de mesa e as enfiam nas suas mãos até atravessar a madeira - para provar algum ponto muito obscuro para o outro. Aqui, contudo, o herói de Armah seria totalmente incapaz de sofrer qualquer ataque (Achebe, 'Africa and her Writers', p. 25). 
A força da crítica de Achebe ao falso universalismo de muitas teorizações eurocêntricas sobre a África deve ser concedida livremente, é claro - como quando ele escreve, em outro ensaio escrito mais ou menos na mesma época, que ele 'gostaria de ver a palavra universal banida por completo das discussões da literatura africana até o momento em que as pessoas deixem de usá-la como sinônimo para o estreito e egoísta paroquialismo da Europa, até que seu horizonte se estenda para incluir todo o mundo' (Achebe, 'Colonialist Criticism', p. 9). No entanto, permanece o fato de que a compreensão de "modernismo" que ele trai em sua discussão sobre The Beautyful Ones é drasticamente atenuada. Confrontado com, para não dizer confundido com, a justaposição no romance de Armah de características alegóricas e realistas, o evidente 'compromisso' na obra 'entre a forma estrangeira e os materiais locais' ${ }^{5}$, ele pode concluir apenas o registo dessa obra - a sua 'aura de tristeza e desespero cósmicos' ('Africa and her Writers', p. 25) - é estranho à África e 'irreconhecível'. O que ele considera o "modernismo" de Armah serve para tornar os The Beautyful Ones "não africano" aos seus olhos.

Mas parece-me que o léxico do 'modernismo' de Armah não é o do 'modernismo internacional' pseudo-universalista amplamente afirmado na literatura

\footnotetext{
${ }^{5}$ Tomo esses termos emprestados de 'Conjectures on World Literature' de Franco Moretti, p. 60.
} 
crítica - se fosse assim, não teria eu qualquer argumento contra Achebe - mas o da literatura mundial, como meus colegas e eu no Warwick Research Collective procuramos definir em Combined and Uneven Development: literatura-mundial, isto é, como "a literatura do sistema-mundial" (WReC, p. 8). Este é um modernismo marcado não por qualquer afeto paradigmático ('desespero', por exemplo), interpretado à luz de um lamento contra uma 'condição humana' existencialmente insuportável, mas sim por sua revelação (seja autoconsciente ou não) de relações complexas entre um universo social local e o mundo mais amplo. 'Neo-colonialismo', o termo que Armah segue Kwame Nkrumah para buscar, é um conceito relacional: ele mapeia relações sociais desiguais entre e através da cidade e vila, cidade e província, nação e região, África e Europa. Quando Achebe acusa Armah de "impor tanta metáfora estrangeira em ... Gana que deixa de ser verdade", e quando ele conclui que "Armah é claramente um escritor alienado, um escritor moderno completo com todos os sintomas de um escrito moderno. Infelizmente, Gana não é um país existencialista moderno. É apenas um estado da África Ocidental lutando para se tornar uma nação ('Africa and her writers', p. 26), acho que ele está perdendo o ponto. Não se trata de termos, por assim dizer, de 'escolher' entre 'África' e 'o Ocidente' - este último decadente, em declínio, 'moderno' mas 
começando a perder o seu monopólio sobre a definição do 'agora'; o primeiro em apuros, emergente, anteriormente contido, mas agora avançando. Em vez disso, somos obrigados a compreender os termos da relação mutante entre 'África' e 'Ocidente' no contexto histórico da descolonização - um divisor de águas histórico, inegavelmente, mas cujo imenso significado ideológico e mesmo político (o fim da ditadura colonial) encontra comparativamente pouca corroboração nas estruturas mais profundas da sociedade: nas relações de classe, na economia, na distribuição de terra e riqueza, etc. 'O fato é que o sistema colonial se tornou um obstáculo ao desenvolvimento dos interesses combinados das camadas privilegiadas africanas e do grande capital ocidental em uma fase expansionista', escreveu Mohamed Lamine Gakou há quase trinta anos. 'Com a independência, o imperialismo removeu todas as barreiras que impediam sua expansão' (Crisis). Isso é verdade para todas as "independências" políticas conquistadas - e, de fato, duramente conquistadas - em todo o continente. Mesmo na África do Sul, como Anne-Maria B. Makhulu disse recentemente, a 'transição para a democracia... não é descolonial nem um local de verdadeira liberdade política. Em vez disso, é um local de novas restrições ditadas precisamente pelo mercado liberalizado' (Makhulu 258-9). Longe de augurar o amanhecer da "liberdade", "independência" nesses 
termos seria melhor conceituada como uma reconstrução racionalizadora da perifericidade e do clientelismo no sistema mundial. É claro que é assim que Armah $o$ conceitua. A forma ferozmente compactada de seu romance - com seu alcance de registros alegóricos, parabólicos e realistas, sua junção de picaresco, jogo de moralidade e realismo crítico, sua mistura de "excrementalismo" e puritanismo quase religioso, e assim por diante - assume significado (como, possivelmente, alguns outros modos formais poderiam ter feito) como um registro e uma crítica da paisagem social realmente existente de Gana nos anos imediatamente após a descolonização.

1 A história de um jovem interiorano que vem à cidade em busca de trabalho ou, mais extravagantemente, em busca da fortuna é um dos topoi centrais da ficção moderna. (Historicamente, essas narrativas apresentam predominantemente homens jovens: mas as narrativas centradas na mulher nunca foram especialmente incomuns ou excepcionais.) De Mine Boy de Peter Abrahams a Germinal de Émile Zola, North and South de Elizabeth Gaskell a Kang Ky tong-ae de From Wonso Pond, e em obras de diferentes épocas e lugares que têm em comum apenas a identidade estrutural de suas situações, a força centrípeta da cidade nos é mostrada. Dickens tem sido uma voz definidora aqui, é claro, tipicamente nos dando a 'vi- 
são de fora' centrada na cidade, por assim dizer, em suas várias representações de Londres como um vórtice vasto e ameaçador, para o qual almas desesperadas são sugadas à vontade. Considere esta passagem de Dombey and Son em que a bondosa e compassiva Harriet Carker contempla a torrente de miséria humana fluindo implacavelmente, embora com passos cambaleantes em direção à cidade grande

Ela muitas vezes olhava com compaixão ... para os retardatários que vinham vagando por Londres, pela grande estrada que ficava perto, e que, com os pés doloridos e cautelosos, e olhando com medo para a enorme cidade diante deles, como se pressentindo que sua miséria não seria senão uma gota d'água no mar, ou como um grão de areia do mar na costa, continuava encolhendo, encolhendo-se diante do mau tempo e parecendo que os próprios elementos os rejeitavam. Dia após dia, esses viajantes se arrastavam, mas sempre, como ela pensava, em uma direção - sempre em direção à cidade. Engolidos em uma fase ou outra de sua imensidão, para a qual pareciam impelidos por um fascínio desesperado, nunca mais voltaram. Alimentos para os hospitais, os cemitérios da igreja, as prisões, o rio, a febre, a loucura, o vício e a morte - eles passaram para o monstro, rugindo ao longe, e se perderam (Dickens, p. 562-563). 
A transformação incessante, irregular e incessante da cidade por meio da modernização é sobre determinada nessas narrativas literárias de país à cidade - gemeinschaft-to-gesellschaft - por ser representada sob o signo do choque do novo, à medida que os protagonistas rurais são levados a confrontar seu ritmo, tamanho, intensidade, brusquidão e impessoalidade cruel. Aqui, por exemplo, está o relato da chegada de Ishvar e Omprakash em Bombaim em A Fine Balance de Rohinton Mistry. Os dois alfaiates fugiram da violência de casta que assola sua aldeia:

Já era noite quando os alfaiates chegaram à cidade. Gemendo e retinindo, o trem entrou na estação enquanto um anúncio retumbava como uma tagarelice nos alto-falantes. Os passageiros foram despejados no mar de amigos e familiares que esperavam. Houve gritos de reconhecimento, lágrimas de felicidade. A plataforma se tornou um redemoinho turbulento de humanidade. Coolies conduzia investidas agressivas para oferecer seus serviços pesados.

Ishvar e Omprakash... abriram caminho através da plataforma e emergiram no gigantesco saguão da estação ferroviária, com seus tetos altos como o céu e colunas tão altas como árvores impossíveis. Eles vagavam atordoados, fazendo perguntas, pedindo ajuda. As pessoas respondiam rapidamente às suas pergun- 
tas, ou apontavam, e assentiam com gratidão, mas não aprenderam nada. Levaram uma hora para descobrir que precisavam de um trem local para chegar ao amigo de Ashraf (Mistry, p. 153). ${ }^{6}$

Como a cidade é tão transparentemente o locus dominante de modernização no sistema-mundo capitalista, tem havido muita discussão na literatura crítica das representações literárias do trabalho urbano. Muito menos tinta crítica foi derramada na discussão da representação literária do trabalho rural nos contextos de modernidade e modernização. Apesar de que se, na modernidade, é óbvio que a cidade puxa, é claro também que o país empurra. 0 narrador

${ }^{6}$ E compare a descrição da chegada de Stephen Kumalo na estação de Joanesburgo em Cry the Beloved Country, de Alan Paton, uma obra muito distante da de Mistry em sua disposição ideológica: '"0 trem para, sob um grande teto, e há milhares de pessoas. Os degraus descem para a terra e aqui está o túnel sob o solo. Negros, brancos, alguns indo, alguns vindo, tantos que o túnel está cheio. Ele vai com cuidado para não bater em ninguém, segurando com força sua bolsa. Ele sai em um grande salão, e as pessoas sobem os degraus, e aqui está ele na rua. 0 barulho é imenso. Carros e ônibus um atrás do outro, mais do que ele jamais imaginou. As pessoas atravessam a rua... mas quando ele começa a atravessar, um grande ônibus passa pelo caminho. Existe alguma lei que ele não entende, e ele recua novamente. Ele se encontra um lugar contra a parede, parecerá que está esperando por algum propósito. Seu coração bate como o de uma criança, não há nada a fazer ou pensar para pará-lo. Tixo, cuide de mim, diz para si mesmo. Tixo, cuide de mim' (1948, p. 17). 
de Hamsun, os trabalhadores migrantes de Armah do norte e os alfaiates de Mistry têm todos em comum não apenas suas migrações para os centros metropolitanos de suas respectivas sociedades, mas também suas esperanças de escapar de vidas experimentadas como cada vez mais duras e empobrecidas. Na ficção de campo para cidade, o campo - o mundo da terra, da aldeia, do trabalho agrícola - é tipicamente representado como uma matriz esgotada e que esgota, cada vez menos capaz de sustentar a vida, não apenas afetiva ou experimentalmente, mas muitas vezes literalmente. ${ }^{7}$ Em Rickshaw de Lao She por exemplo, o protagonista central, 'Camel' Hsiang Tzu (Xiangzi), foge de uma vida rural composta de forma tão indiferente por "camadas de suor sangrento e dor amarga" que ele mal consegue falar sobre isso (Lao She 221); e quase a mesma história de fundo está por trás do movimento de personagens do campo para a cidade em busca de trabalho em inúmeros outros romances, contos, poemas e peças de teatro.

${ }^{7}$ Lembramos a sugestão de Jameson, com referência às pinturas de Van Gogh, de que 'uma maneira de reconstruir a situação inicial à qual a obra é de alguma forma uma resposta é enfatizando as matérias-primas, o conteúdo inicial, que confronta e retrabalha, transforma e apropria. Em Van Gogh, esse conteúdo, essas matérias-primas iniciais, devem ... ser apreendidos simplesmente como todo o mundo objeto da miséria agrícola, da pobreza rural inicial e todo o mundo humano rudimentar de trabalho árduo do camponês, um mundo reduzido ao seu estado mais brutal e estado ameaçado, primitivo e marginalizado' (Postmodernism, p. 7). 
Há um importante corpus de trabalho literário moderno dedicado à tarefa de descrever a vida daqueles que permanecem para trás na fazenda e na aldeia, trabalhando na terra, quando tantos de sua coorte - companheiros da aldeia, vizinhos, amigos e membros da família - partem para procurar trabalho na cidade. Em The Country and the City, Raymond Williams identifica três linhas principais de desenvolvimento na escrita britânica, preocupadas com o avanço da residualidade da experiência rural de cerca de 1870 em diante. Primeiro, há o chamado romance 'regional', "com algumas de suas raízes em George Eliot e Hardy". Em segundo lugar, há 'um desenvolvimento, talvez originado em Meredith, de sentimentos sobre a terra e sobre o crescimento natural, que em um modo continua formas de descrição da paisagem e poesia da natureza, na linguagem verde de Clare, mas em outro modo é uma imagem das relações humanas e especialmente do amor e do desejo'. Finalmente, há uma proliferação do que, em outros contextos, às vezes tem sido chamado de 'etnografia de resgate' (o termo não é usado pelo próprio Williams): 'memórias, observações, relatos da vida rural: muitos deles permeados por um sentido de o passado que se desvanece... mas outros centraram-se nos usos e abusos da terra, nas relações com um mundo natural ameaçado e nas condições de um ambiente humano'. Conforme Williams os reúne, es- 
sas três linhas de desenvolvimento são complexas e contraditórias. Na verdade, suas complexidades são tais que não é possível para nós chegarmos a quaisquer julgamentos sumários: 'muitos dos problemas surgem do fato de que sentimentos verdadeiros e falsos, ideias verdadeiras e falsas, histórias verdadeiras e falsas, posicionam-se muito próximas, muitas vezes dentro do mesmo trabalho' (Williams, p. 248).

Publicado em 1973, a discussão de Williams pressagia de forma iluminadora a escrita ainda por vir e além de seu alcance. Pode-se pensar na trilogia de John Berger, Into Their Labours, por exemplo, que trata da experiência do campesinato alpino ao longo do século XX; 8 ou - em outro lugar na Europa - o grande romance de Wiesław Myśliwski, Stone upon Stone, do qual deduzi o título deste ensaio e sobre o qual terei mais a dizer em um momento. Pode-se, é claro, usar a discussão de Williams também como uma lente para alguns dos escritos sobre a vida rural nas literaturas da Europa não anglófona desde meados do século XIX: o grande corpo da literatura russa, por exemplo - Dmitry Grigorovich, Ivan Turgenev, Anton Chekhov, Leo Tolstoy, Nikolai Leskov; a rica tradição polonesa que se estende de Władysław Stanisław Reymont a

\footnotetext{
${ }^{8}$ Os três volumes da trilogia de Berger são Pig Earth (1979), Once in Europa (1987) e Lilac and Flag (1990). Algumas das discussões críticas da trilogia colocaram-na conscientemente em relação a Williams e as ideias de "salvamento" e lembrança histórica. Veja, por exemplo, Kaye e Schmitt-Kilb.
} 
Myśliwski e além; a obra do islandês Halldór Laxness, do sueco Vilhelm Moberg ou do espanhol Ramón J. Sender; e assim por diante. No entanto, qualquer discussão sobre as representações literárias do trabalho rural na era moderna exige que pensemos preliminarmente em duas questões em particular. A primeira delas diz respeito à concepção popular dominante da vida rural como estando de alguma forma fora, além ou abaixo da história moderna, deixada para trás pelas forças da modernização e existindo no mundo contemporâneo apenas como uma espécie de relíquia - inalterada e imutável, do mesmo jeito que sempre esteve e, por isso mesmo, à beira da extinção em um ambiente social capitalista marcado pela "constante revolução da produção, perturbação ininterrupta de todas as condições sociais, [e] incerteza e agitação eternas" 9 . A segunda diz respeito ao problema da representação: nas obras literárias que tratam da vida rural, e especialmente do campesinato, qual é a visão de classe da narração? Qual é a relação entre a voz falada (e a ideologia ou consciência social que a governa) e os personagens, práticas sociais, ideias e convenções faladas ou expressas? Como podemos levar essas questões em consideração em nossa leitura das obras literárias que nos interessam?

${ }^{9}$ As palavras de Marx e Engels, é claro, em Manifesto of the Communist Party, p. 36. 
No que diz respeito à relação da vida rural com a modernidade, o ponto-chave que precisa ser indicado - além mesmo das ideias de dependência ou do "desenvolvimento do subdesenvolvimento" - é que o desenvolvimento capitalista envolve (e só é possível com base em) uma reestruturação massiva e mundial da natureza, das relações sociais e do meio ambiente. Há muito a aprender com os estudiosos que escrevem hoje sob a rubrica de 'ecologia mundial', que têm procurado demonstrar que a produção de capital é também e ao mesmo tempo a produção da natureza, ou pelo menos que envolve uma reprodução amplamente transformadora da natureza. Em seu ensaio de duas partes, 'Amsterdam is Standing on Norway' (2010), por exemplo - o título já aponta de forma iluminadora para o argumento do ensaio - Jason W. Moore mostrou que as 'fronteiras de commodities mercadorias' que foram criadas no desenvolvimento da capital holandesa no longo século XVII, e da qual dependia a "ascensão" de Amsterdã, impactou decisivamente o meio ambiente e as relações sociais não apenas na própria Holanda, mas em todo o norte da Europa, Américas, África e sudeste da Ásia - uma vasta extensão do globo atravessado pelo Atlântico Norte e Sul, os oceanos Índico e Pacífico:

De seus postos de comando em Amsterdã, a capital holandesa implantou prata ame- 
ricana na criação de sucessivas fronteiras dentro da Europa, transformando as regiões escandinava e báltica. 0 caráter de fronteira dessas transformações foi decisivo, com a premissa de colocar na órbita do capital suprimentos de terra e força de trabalho prontamente exploráveis. Vemos no norte da Europa exatamente o que vemos nas Américas - um padrão de transformação ambiental centrada em commodities e, portanto, relativa exaustão ecológica, da qual a única saída foi a conquista global renovada e ciclos cada vez maiores de desenvolvimento combinado e desigual (Pt. II, p. 188).

Os historiadores que criticaram as reivindicações europeias seletivas por terem "avançado" sociedades africanas ou asiáticas nos longos anos de dominação colonial, às vezes observaram de forma acerba que '[o] camponês ... entrou no domínio colonial com uma enxada e saiu com uma enxada' (Lonsdale, p. 614). A sugestão deles não é que a modernidade colonial contornou as populações camponesas e deixou a cultura camponesa intacta, mas que incorporou e empobreceu o campesinato. Longe de ser uma classe atrasada deixada para trás com o passar do tempo, o campesinato global fez parte da história da modernização capitalista. Um corolário chave aqui - e o qual achamos que está sendo enfatizado repetidamente na obra literária relevante - é que a vida camponesa, 
na era moderna, não permanece a mesma de sempre, mas está sujeita a pressões e demandas em constante mudança. Como John Berger afirma,

Os camponeses convivem com mudanças de hora em hora, diariamente, anualmente, de geração em geração. Quase não há uma constante dada a suas vidas, exceto a constante necessidade de trabalho. Em torno desse trabalho e das estações do ano, eles próprios criam rituais, rotinas e hábitos a fim de arrancar algum significado e continuidade de um ciclo de mudança implacável: um ciclo que é em parte natural e em parte o resultado do girar incessante da pedra de moinho do economia na qual eles vivem (Pig Earth, p. 207).

Voltemos agora à questão da representação. Aqui, o que precisa ser dito parece óbvio, mas tem consequências muito importantes. É que o que nos é dado em uma obra literária é sempre um objeto situado ou relacional - nunca aquele objeto como ele é no mundo extra-literário, mas sim uma representação dele como visto de um ponto de vista específico e mediado por uma forma na própria obra literária. Uma das afirmações clássicas dessa ideia é fornecida por Bakhtin e Medvedev em The Formal Method in Literary Scholarship, sua 'Introdução crítica à poética sociológica', publicada pela primeira vez em 1928. Em 
um momento deste estudo, os autores voltam sua atenção para 'a interrelação entre o horizonte ideológico refletido e a estrutura artística dentro da unidade da obra literária"; para esclarecer seu argumento, eles nos convidam a pensar no personagem de Bazárov, no romance de Turgueniev, Fathers and Sons:

O herói de um romance, por exemplo, Bazárov de Fathers and Sons, de Turgenev, se retirado da estrutura romanesca, não é de forma alguma um tipo social em sentido estrito, mas é apenas a refração ideológica de um determinado tipo social. Os estudos de história socioeconômica definem Bazarov como um raznochinets. Mas ele não é um raznochinets em seu ser real. Ele é a refração ideológica de um raznochinets na consciência social de um grupo social definido, a nobreza liberal à qual Turgenev pertencia (Bakhtin and Medvedev, p. 21).

Uma nota de rodapé escrita pelo tradutor inglês de Bakhtin e Medvedev, Albert J. Wehrle, explica que o termo 'raznochinets' identifica 'um membro da "nova classe" que começou a aparecer por volta do final do século XVIII para atender às necessidades de desenvolvimento do capitalismo russo. Sua educação os separou da classe baixa de sua origem. Bakhtin e Medvedev estão dizendo que a representação de Bazárov em Fathers and Sons não é a de um membro do 
raznochintsy, visto que essa nova fração de classe realmente existe - e que pode ser construída, com base nisso, como um objeto de conhecimento em estudos socioeconômicos - mas é antes uma representação de como um membro da nova fração de classe pode ser visto por um membro da nobreza liberal (como Turgenev), que estava, além disso, interessado em enquadrá-lo como protagonista de um romance ambientado no contexto do declínio do liberalismo aristocrático e o surgimento de filosofias sociais mais radicais (niilismo, especialmente, nesta obra) entre as classes sociais emergentes, incluindo os raznochintsy. No romance, quase sempre vemos os pensamentos e ideias de Bazárov em contraponto com os de outras figuras, situadas de forma diferente na ordem social que ele: Pavel Petrovich, com quem ele se choca de forma mais evidente, mas também Nikolai Petrovich e Anna Sergevna Odintsova. Não é apenas que os pensamentos e ideias de Bazárov são apresentados como sendo diferentes daqueles desses outros personagens. É antes, e mais significativamente, que eles são apresentados por meio dessa diferença. As opiniões e disposições ideológicas do amigo de Bazárov, Arkady, e do pai de Arkady, Nikolai Petrovich, são focalizadas no romance. Eles estão em seus próprios pés, por assim dizer. 0 discurso no romance é invariavelmente representativo socialmente: Nikolai, Arkady, Pavel dizem as coisas que dizem, acreditam nas 
coisas que acreditam, por causa de quem são como tipos sociais estabelecidos e reconhecíveis, em relação uns aos outros e à sociedade em geral. Mas com Bazárov é diferente: quer ele esteja falando sobre política, história e o estado da nação, ou sobre beleza, amor e paisagem, suas visões e ideias são "fundadas" menos em si mesmas do que em sua distância das outras personagens. Isso é assim mesmo que suas opiniões e ideias demonstrem possuir o poder do emergente: um arauto do futuro, da Rússia em formação, as ideias de Bazárov desafiam e ameaçam as dos outros personagens do romance, representantes de ambas as ordens sociais residuais e atualmente dominantes. Considere a seguinte passagem perto do início do romance. Arkady e Bazarov viajaram de Moscou, onde estudaram juntos, para as províncias onde o pai de Arkady, um senhorio liberal de recursos muito limitados, mantém uma propriedade modesta, agora em declínio substancial e em degradação. Conforme ele e Bazarov se aproximam da propriedade, os sentimentos de Arkady são descritos:

Os lugares por onde estavam viajando dificilmente poderiam ser chamados de pitorescos ... Avistaram-se pequenos riachos com margens vazadas, e os menores lagos de moinho com barragens frágeis e pequenas aldeias com cabanas baixas de camponeses sob telhados escuros, muitas vezes com metade de 
sua palha já desaparecida, e pequenos celeiros de debulha, todos inclinados para um lado com paredes feitas de galhos trançados e aberturas ao lado de celeiros de feno dilapidados, e igrejas, tanto de tijolos, dos quais o alguns caídos, ou de madeira com cruzes desordenadas e cemitérios abandonados e destruídos. Arkady sentiu uma pressão crescente no coração. Como se deliberadamente, todos os camponeses que encontraram estivessem com roupas esfarrapadas e cavalgando maltrapilhos. Os salgueiros à beira da estrada eram como mendigos em farrapos, com casca rasgada e galhos quebrados. Emaciadas, com pelo áspero, quase ossos nus, vacas mastigavam avidamente a grama em valas. Foi como se eles tivessem apenas naquele minuto escapado das garras de algumas garras mortais e temíveis - e, convocados à existência pela visão miserável desse gado enfraquecido, surgiu no meio do belo dia de primavera o espectro branco de inverno sem fim e sem alegria com nevascas, geadas e neves... (Fathers and Sons, p. 12).

Pode ser que Arkady esteja chocado ao descobrir o quanto a propriedade de seu pai diminuiu desde a última vez que a viu. Pode ser que a consciência social que ele desenvolveu quando estudante em Moscou o tenha tornado sensível agora à dilapidação da propriedade, onde ele não era tão sensível antes. Mas está claro nesta passagem que seus sentimentos de 
consternação e até vergonha são uma consequência direta de ele ver a propriedade como ele acredita que Bazárov deve estar vendo - e julgando - a. A degradação da propriedade é uma coisa: a pobreza é lamentável, sem dúvida. Mas Arkady sente que Bazárov deve sentir que a dilapidação da propriedade é escandalosa, em vez de "meramente" lamentável. E ele se sente envergonhado e ansioso - "uma pressão crescente em seu coração" - como resultado.

É amplamente reconhecido, pelo menos desde a época das Éclogas de Virgílio, que quase todas as representações literárias dos trabalhadores rurais são escritas, de toda a divisão social do trabalho, por escritores que não são membros dessa classe. 'Meus escritos sobre os camponeses me separam e me aproximam deles', como Berger escreve em Pig Earth (p. 7). Na verdade, o problema do que Bakhtin e Medvedev chamam de "refração" não é mais evidente do que no caso da representação literária do campesinato. Qualquer um que tenha lido Piers Plowman saberá que nem sua descrição denunciatória de 'desperdiçadores' ociosos - que não trabalharão a menos que sejam pagos - nem sua descrição comemorativa do lavrador honesto, Piers - que 'aceita que é seu dever produzir alimentos para o benefício de toda a sociedade em troca da manutenção da lei e da ordem pela aristocracia' (Dyer 29) - devem ser tomadas ao pé da 
letra. Quando encontramos "camponeses" ou "trabalhadores rurais" em obras literárias, estamos de fato encontrando uma expressão de uma relação social com esses trabalhadores - a "refração ideológica de um determinado tipo social". Considere o seguinte exemplo extremo - uma descrição localizada no parágrafo de abertura de "Tatyana Borisovna and her Nephew", extraída dos primeiros trabalhos de Turgueniev, Sketches from a Hunter's Album:

Dê-me sua mão, caro leitor, e venha dar um passeio. 0 tempo está bonito. 0 céu de maio brilha com um azul suave. As folhas novas e lisas do salgueiro brilham como se tivessem sido lavadas. A estrada larga e plana é inteiramente coberta por aquela grama curta de talos avermelhados que as ovelhas adoram roer. À esquerda e à direita, ao longo das longas encostas das colinas baixas, o centeio verde ondula silenciosamente. As sombras de pequenas nuvens deslizam sobre ele como glóbulos de umidade. À distância, bosques escuros cintilam, lagoas cintilam e aldeias cintilam amarelo. As cotovias sobem às centenas, cantam e caem precipitadamente e, com pequenos pescoços esticados, são vistas conspicuamente em pequenos afloramentos de solo. As torres param na estrada, olham para você, agacham-se para deixá-lo passar e, dando alguns pulos, voam pesadamente para o lado. Em um planalto abaixo 
de um vale raso, um camponês está arando. Um potro malhado com rabo curto e crina eriçada corre com pernas incertas atrás de sua mãe e pode-se ouvir seu relincho estridente. Nós caminhamos em direção a um vidoeiro... (Turgenev, Sketches, p. 204).

Em um aspecto, pelo menos, sua passagem não é típica da obra de Turguenev em geral - marcada como isso por sua sensibilidade bastante exemplar às dificuldades da vida camponesa e sua preocupação com o declínio dos recursos econômicos, sociais e culturais do campesinato no final Rússia do século XIX. [Outro exemplo para mostrar que não é tão atípico] Mas eu o cito porque sua redução da figura do camponês à natureza, tão completa a ponto de ser quase completa, não é incomum no corpus literário mais amplo. 0 lavrador aqui não é mais nem menos do que um elemento da natureza: seu trabalho é considerado tão pouco social quanto o das gralhas e das cotovias, que de fato comandam mais espaço narrativo do que ele. 'As cotovias crescem às centenas... Em um planalto abaixo de um vale raso, um camponês está arando'. É o que os camponeses fazem - eles aram, assim como as cotovias sobem. O tempo está bonito; é um lindo dia de primavera: portanto, há cotovias na floresta, gralhas à beira da estrada, potros recém-nascidos dando cambalhotas... e camponeses 
arando. Não podemos ler esta passagem sem perguntar sobre o ponto de vista do narrador que vê as coisas desta forma - a palavra "ponto de vista" gesticulando não apenas para uma posição de classe, mas para uma ideologia, um modo de viver e de expressar essa posição de classe. E Turgenev já nos aponta nessa direção, obviamente: 'Sketches from a Hunter's Album'.

Podemos ficar com a literatura russa para considerar mais um estereótipo, diferente do que acabamos de discutir, mas igualmente onipresente na representação literária do campesinato: a ideia do camponês como tímido para o trabalho, sua produtividade potencial indisponível e não realizada por causa de sua recalcitrância. Encontramos um exemplo espirituoso desse estereótipo no conto de Chekhov de 1886, 'Agatha', no qual o narrador, escrevendo sobre a divisão social do trabalho, nos apresenta a Sava Stukach, que zela pela horta comunitária da vila de Dubovka:

Savka era um jovem de 25 anos, alto, bonito e duro como um tijolo. Ele tinha fama de astuto e bom senso, sabia ler e escrever e raramente bebia vodca; mas, por mais poderoso e jovem que fosse, como operário não valia um copeque de cobre. Embora duro como um chicote, seus músculos fortes estavam impregnados de uma indolência pesa- 
da e invencível. Como todos os outros na aldeia, ele vivia anteriormente em uma cabana própria e tinha sua própria parte da terra, mas não havia arado, semeado, nem feito comércio. A velha mãe mendigava de porta em porta enquanto ele vivia como os pássaros do ar, sem saber de manhã o que comeria ao meio-dia. Não era vontade, nem energia, nem pena da mãe que faltava; ele simplesmente não sentia inclinação para o trabalho árduo e não via a necessidade disso. Uma sensação de paz e uma paixão inata, quase artística, por uma vida ociosa e desordenada emanava de todo o seu ser. Quando seu corpo jovem e saudável ansiava por exercícios musculares, o rapaz se abandonava completamente por um curto período de tempo a alguma ocupação desenfreada, mas absurda, como afiar muitas estacas inúteis ou disputar corridas com as mulheres. Seu estado favorito era de imobilidade concentrada. Ele era capaz de permanecer por horas em um lugar, imóvel, e com os olhos fixos no mesmo lugar... (Chekhov, p. 26).

Todos os elementos aqui são significativos. Temos o privilégio de classe do próprio narrador, para começar, ampliado por sua evidente insensibilidade às formas como isso condiciona ativamente a construção de sua caracterização de Savka. Internamente, 
vemos a musculatura e a força de Savka sendo enquadradas como força produtiva latente, de forma que seu fracasso em colocar essa força em prática na forma de trabalho surge como perverso. As relações sociais prevalecentes que comutam a força física, por um lado, em trabalho assalariado, por outro, são naturalizadas na passagem, embora possamos ter um vislumbre da natureza exploradora dessas relações na afirmação de que 'como um trabalhador [Savka]... não valia um copeque de cobre'. O que falta a Savka é uma ética de trabalho: "ele simplesmente não sentia inclinação para o trabalho árduo e não via a necessidade disso". Mas no que diz respeito ao 'trabalho', o narrador não pode vê-lo como poderia se apresentar a Savka - duro, difícil, pouco recompensador, extenuante -, mas apenas em termos abstratos (e marcadamente ideológicos), como 'melhorando' e estabilizando socialmente: 'Um sentido de paz e uma paixão inata, quase artística, por uma vida ociosa e desordenada emanava de todo o seu ser'.

É impressionante, claro, que o narrador 'produtivista' desta história classifique a 'ociosidade' de Savka como 'quase artística'. Pois, em algumas de suas maiores histórias, Tchekhov explicitamente nos apresenta as figuras de artistas cujo distanciamento relativo das relações sociais de produção vigentes lhes permite vislumbrar a violência dessas relações. 
No extraordinário confronto entre o narrador artista de The House with the Mansard' (1896) e Lida, uma reformista social, por exemplo, lemos a resposta do narrador ao argumento de Lida de que um posto médico precisa ser estabelecido em Malozemovo porque os camponeses estão morrendo por falta de tratamento. Uma jovem, Anna, acaba de morrer no parto. 0 narrador responde assim:

O que importa não é que Anna morreu no parto, mas que Anna, Martha e Pelagea devem renunciar ao trabalho de manhã à noite, adoecer de trabalho árduo, passar a vida inteira se preocupando com seus filhos famintos e doentes, com medo da morte e doenças, medicam-se por toda a vida, murcham cedo, envelhecem cedo e morrem na sujeira e no fedor. Assim que seus filhos crescem, seguem o exemplo de suas mães, e assim se passam centenas de anos, milhões de pessoas vivendo em condições piores que os animais, apenas para ganhar um pedaço de pão, para viver no medo perpétuo (Chekhov, p. 152).

Uma descrição muito diferente do trabalho camponês - e da vida camponesa - pode ser encontrada em Stone upon Stone de Myśliwski, publicado pela primeira vez em 1999, um romance vasto, extenso 
e inesgotavelmente rico que se contrapõe à grande extensão da história polonesa no século XX. A maior conquista de Myśliwski na obra é, sem dúvida, a criação de seu protagonista-narrador, Szymon Pietruszka, cujo monólogo compreende o romance em sua totalidade. Nomeado em homenagem a Simon Peter, o primeiro apóstolo, pescador que se tornou pescador de homens, Szymon - quase todo mundo que ele conhece o chama pelo nome de animal de estimação, Szymek - compartilha alguns dos atributos e falhas de seu homônimo bíblico: ele é teimosamente independente, impulsivo, impetuoso, corajoso e profundamente insensível às expectativas sociais ou contextuais, qualidades que salvam sua vida em várias ocasiões, mas assumem forma em outras ocasiões como perversidade ou teimosia. Um autor da palavra - também como Simon Peter - e possuidor da rara habilidade de comover as pessoas com seus contos e histórias, a "tipicidade" de Szymek, no entanto, não é a de qualquer tipo de personagem literário padrão. De temperamento quente, sujeito à violência, muitas vezes insensível, fanático e desdenhoso das mulheres em geral, ele é desagradável - na verdade, em muitos aspectos positivamente desagradável; obviamente não um homem comum virtuoso, mas também radicalmente singular e inalcançável para servir como o estereótipo de um patife bucólico ou caipira. 
Um de quatro filhos, Szymek tem que cuidar da fazenda da família depois que seus pais morrem. Ele é um improvável tradicionalista. Ele odeia o trabalho da agricultura e a existência miserável que ele exige - "Prefiro sentar-me atrás de uma mesa do que carregar repolho", como ele disse a si mesmo em uma ocasião (Myśliwski, Stone, p. 224). Enquanto crescia, ele pensava em escapar da fazenda e da fúria de seu pai, que o via como um perdulário. Mas seus dois irmãos mais novos trocam a vila pela cidade antes mesmo de 1939, e a violência assassina da ocupação nazista deixa seu irmão mais velho, Michał - que, como Szymek, sobrevive à guerra enquanto trabalhava no movimento de resistência clandestina - sem-terra, preso em um poço de silêncio do qual ele nunca consegue escapar. (Vale a pena fazer uma pausa para medir o fato de que mais de um quinto da população polonesa total - cerca de seis milhões de pessoas - morreu entre 1939 e 1945 como resultado direto da brutalidade deliberada e destruidora mundial das forças de ocupação alemãs.) Szymek é deixado para trás para cuidar de Michał, da fazenda e de suas terras da melhor maneira que puder.

Mas se o destino impôs esse fardo sobre ele, isso não quer dizer que ele jamais se reconcilie com ele. Szymek não é pastor. Seus relatos sobre a labuta diária do trabalho camponês - isto é, do trabalho rotinei- 
ro, das dificuldades rotineiras, da pobreza rotineira - são gloriosamente, indomavelmente, vivos com resmungos e reclamações (o que em iídiche seria chamado de kvetching): isso dói, isto é pesado, isso é uma grande perda de tempo, que não compensa, e assim por diante:

Muitas vezes tentei convencer meu pai a comprar uma máquina de colheita automática, porque estava farto de tanto cortar o pasto. 0 fato de a colheita ter que ser feita todos os anos é algum castigo de Deus? 0 crescimento não poderia ser diferente, para que não precisasse ser ceifado, amarrado e transportado, e depois debulhado, peneirado e levado para o moinho, e aí, só então, termos pão? 0 pão pode crescer já como pão desde o início; bastaria sair e coletar os pães direto do chão. Eles poderiam até ser pequenos, como do tamanho de cabeças de repolho. Não pequenas sementes que dão um trabalho imenso.

Mas meu pai não concordaria. Não podemos pagar por isso e, além disso, o feno fica reto quando você o corta, mas as colheitadeiras bagunçam, então não serve para consertar a palha, fazer palha ou encher colchões (p. 77-78).

Seria tautológico dizer que a forma de pensar de Szymek é materialista. 0 que mais poderia ser? Sua abordagem da vida é prática, pragmática, terrena. A 
quais características devemos acrescentar outras, derivadas de seu temperamento particular: teimoso, impaciente, ácido. Ele emerge para nós como uma espécie de contrapartida rural dos "filósofos proletários" que Jonathan Rée discutiu em um livro seu sobre a subestrutura intelectual da cultura da classe trabalhadora na Grã-Bretanha no início do século XX. (1984). ${ }^{10}$

Tendo sobrevivido à violência da ocupação alemã, a turbulência da sovietização pós-1945 e a interminável austeridade da vida camponesa (a fome está sempre presente no romance, e a ameaça de uma fome insuperável assombra todo inverno); tendo visto muitas mudanças, visto coisas sendo feitas e cultivadas - madeira, ferro, vagões, tumbas, móveis, linho assim como trigo, centeio e também batatas; tendo trabalhado em várias funções diferentes além de ser agricultor - contador fiscal, registrador de casamento - Szymek sabe muito sobre muitas coisas e tem muitas histórias para contar. Mas o mesmo acontece com muitas outras pessoas que passaram pelos tipos

${ }^{10}$ Jonathan Rée, Proletarian Philosophers: Problems in Socialist Culture in Britain 1900-1940. Oxford, Oxford University Press, 1984. 
de coisas que ele passou. ${ }^{11} \mathrm{O}$ que o torna incomum é que ele também é um homem dado à reflexão e determinado a colocar as coisas no devido contexto, para apreendê-las em sua particularidade, ao mesmo tempo em que compreende seu significado em um quadro mais amplo. Observando que a velha estrada através da aldeia era sinuosa, ele acrescenta ironicamente que "as estradas costumam ser. Elas têm que contornar uma coisa ou outra. Um santuário, um lago, uma casa'(p. 57). 'Você pegou [a estrada] ... para chegar ao mercado na cidade, ou em outras aldeias por aqui', ele nos conta, 'e se você estivesse indo para a guerra ou indo para o mundo exterior, a estrada o levaria até lá do mesmo jeito exato'(p. 55). Filosofia caseira - lembramo-nos novamente de Berger: "Ao amanhecer o frio se intensifica. As macieiras estavam pretas

${ }^{11}$ Uma formulação diferente dessa ideia pode ser encontrada no posterior A Treatise on Shelling Beans, no qual o narrador de Myśliwski reflete sobre a 'mistura de pessoas' que ele encontrou enquanto trabalhava em um canteiro de obras após a guerra: todos lá haviam passado por coisas extraordinárias - e experiências extraordinariamente duras e brutais: 'Pedreiros, operários de concreto, gesso, soldadores, eletricistas, operadores de guindastes, motoristas, entregadores, todos os tipos, mesmo nos escritórios, e descobriria que um deles era uma coisa, outro tinha sido outra coisa, um era daqui, outro de lá, eles estiveram em acampamentos, prisões, um exército ou outro, eles lutaram no levante, na floresta, eles tiveram problemas renais por terem apanhado, a eles faltavam dentes ou unhas, não pareciam ter a idade que tinham, ou ainda eram muito jovens, mas já tinham cabelos grisalhos. Cada canteiro de obras naquela época era uma verdadeira Torre de Babel, não de idiomas, mas do que poderia acontecer às pessoas" (p. 171-172). 
na névoa branca. Não havia cor em lugar nenhum e, além do pátio, nenhum som. 0 vento nordeste estava soprando. Ele penetra nas roupas mais grossas e sopra nos próprios ossos uma lembrança da morte. Faz com que as vacas deem menos leite. Isso torna a terra dura como uma rocha. "Não há nada mais triste do que uma morte", disse Marie, "e nada que seja esquecido mais rapidamente" (Pig Earth, p. 18). Em Szymek, o que é conhecido ou foi visto ou experimentado tornou-se sabedoria, por mais rude, incomum e mesmo contra-intuitivo que possa ser:

É difícil acreditar que o avô foi supostamente a primeira pessoa na aldeia a pensar em um arco no cabo de uma foice. Ele pensou ou viu em algum lugar, as pessoas diziam coisas diferentes. Algumas pessoas achavam que ele devia ter visto no caminho de volta da guerra. Em algum lugar as pessoas ceifavam com aros em suas foices, e quando ele voltou começou a cortar assim com sua própria foice. Quer dizer, o que havia lá. Um pedaço de haste de carvalho, dois furos na empunhadura, qualquer um poderia ter pensado nisso. Além disso, existem algumas coisas que ninguém precisa pensar, porque elas simplesmente estão lá. Um chicote, por exemplo. Ele está lá e você o usa quando o cavalo não 
puxa. Deve ter vindo com o cavalo. Ou o telhado de uma casa, rodas em um carrinho, solas de botas (p. 16-17).

A noção de que o chicote "deve ter vindo com o cavalo" é um toque soberbo: espirituoso, caprichoso, absurdo e absurdista - é o tipo de coisa que só poderia ser dita por quem sabe como encantar as pessoas com histórias. Isso nos abre para outro aspecto fermentador do caráter de Szymek: sua profunda curiosidade intelectual sobre o mundo e seus caminhos - um interesse não apenas em como as coisas funcionam, mas em como as pessoas vivem. Seria muito forte descrever esse interesse como "humano". Não é bem isso, e claro, nem remotamente cosmopolita. Mas abre uma linha de visão para uma sutileza de discernimento e até mesmo uma sensibilidade que ele evidentemente prefere não apresentar muito imediatamente ou com muita frequência em suas relações sociais regulares. Essas últimas qualidades são mais marcadas em suas lembranças dolorosamente tristes de seu tempo com Małgorzata, a única mulher em sua vida (além de sua mãe, talvez) a quem se pode dizer que amou verdadeiramente, mas que, no entanto, perde por causa de um sintoma incapacidade de agir sobre seus sentimentos. Em uma passagem extraordinária, Szymek lembra que costumava ir à casa de Małgorzata depois do trabalho, quando ambos eram 
empregados pela administração distrital criada pelo novo governo comunista após a guerra. Uma vez lá, ela iria imediatamente começar a fazer as tarefas domésticas, e ele a observaria. Ele primeiro descreve sua "alimentação, água, lavagem e limpeza", palavras que mostram que ele está ciente de seu trabalho, mas de uma forma relativamente livre. Mas, à medida que ele continua, o foco de sua referência linguística aguça consideravelmente:

Enquanto a observava, mal conseguia me reconhecer ... às vezes tinha a sensação de que o próprio trabalho passava por ela de mão em mão, que os móveis a moviam pelo quarto. Um balde cheio de espuma de sabão é uma coisa pesada até para um homem, mas antes que eu percebesse e pulasse para ajudá-la, ela o agarrava pelas alças e o arrastava para a passagem... Ou quando ela raspava cenouras para a sopa. Você pensaria que as cenouras não eram nada de especial. Mas toda a sala ficou vermelha, como se o sol estivesse se pondo vermelho quando um vento forte está chegando. Na verdade, tudo que ela precisava fazer era ficar no fogão mexendo uma das panelas com uma concha, que, mesmo assim, toda a sala ficava cheia dela, cada canto e recanto, enquanto o resto de nós, seu pai, sua mãe e eu, estávamos espremidos no canto mais ínfimo (p. 385-386). 
Ele não questiona a carga colocada sobre Małgorzata pela divisão sócio-sexual do trabalho, notavelmente. Depois do trabalho, ela vai trabalhar, enquanto ele se senta e conversa com seu pai. Mas ele vê - e muito claramente - quanto trabalho há para ela fazer, e quão árduo é. Embora sua atenção seja atribuída substancialmente ao desejo sexual - "aqueles braços brancos dela cobertos até os cotovelos em purê de batata, em seu avental, com seus chinelos velhos"; seus seios "galopando sob a blusa como cavalos de casamento" (p. 386) - não pode ser reduzido a isso. A sensação de calor por dentro é uma coisa. Podemos ser cautelosos sobre isso. Mas a sugestão de que, enquanto a observava, mal conseguia se reconhecer, parece tender para outra direção, assim como a observação de que vê-la trabalhando "ocupou o lugar do pensamento ou das palavras para mim". Ele nota tudo o que ela faz: misturar comida para os porcos, lavar o chão, colocar lenha no fogão, enrolar massa, fatiar bolinhos, raspar cenouras, alimentar as galinhas, costurar botões, varrer... . Este é um trabalho que ela faz sem remuneração; e também não para ela, mas para os outros, incluindo Szymek. Na verdade, é a natureza abnegada de seu trabalho doméstico que o emociona particularmente: mas também o perturba. Quando ele diz que "às vezes tinha a sensação de que o próprio trabalho passava por ela de mão em mão", ele vê não apenas que o trabalho é interminável, mas 
também que não é considerado qualquer tipo de compensação. Se for experimentado como um fardo (e não estamos em posição de nos capacitar para julgar isso), também é internalizado como uma expressão de amor familiar ou compromisso. 0 registro expressionista introduzido - "Você pensaria que cenouras não eram nada de especial. Mas toda a sala ficou vermelha, como se o sol estivesse se pondo vermelho quando um vento forte está chegando" - deve ser decodificado como um correlativo objetivo da qualidade oceânica do amor de Małgorzata por sua família. É o que a liga ao seu mundo. Mas é precisamente isso, creio, que faz Szymek hesitar, deixando-o incapaz de dar um passo à frente. A aceitação de Małgorzata do mundo dado não é algo que ele possa abraçar por si mesmo. Embora ele possa desejar fundir sua vida com a dela, ele descobre que não pode. "A questão fatídica para a espécie humana me parece ser se e em que medida seu desenvolvimento cultural conseguirá dominar a perturbação de sua vida comunal pelo instinto humano de agressão e autodestruição", Freud escreve em Civilization and Its Discontents (p. 92). Algo em Szymek interpreta o amor feminino criador de comunidade de Małgorzata como ameaçador - não para sua masculinidade, como tal, mas para a teimosia, a impulsividade iconoclasta e antissocial, que é certamente uma parte considerável de como ele se 
apresenta socialmente. Ele se imagina morrendo, ao invés de viver, no amor de Małgorzata:

Parecia que ela estava apenas fazendo uma coisa simples como costurar um botão em uma fronha. Não era só que o botão parecia deslizar na agulha e linha por conta própria. Mais do que isso. Às vezes eu tinha vontade de colocar minha mão sob a agulha e dizer:

"Pique-me, deixe sangrar. Talvez o sangue diga o nosso futuro." E o sangue gotejava e gotejava, então fluía, então jorrava em um riacho, um rio, até que a morte viesse (p. 386).

Não é, obviamente, que Szymek não esteja interessado na comunidade. Pelo contrário, seus relatos sobre as mudanças que ocorreram na aldeia e sobre as perdas em que ele pessoalmente sofreu, e que muitas das pessoas que ele conhece incorreram, nos longos, turbulentos e socialmente dizimadores anos do século XX, estão imbuídos de uma profunda generosidade emocional. 0 registro de sua linguagem nessas passagens carrega uma ressonância afetiva, um produto da lacuna entre o substrato terrestre - e mesmo terreno - de sua consciência e sua conceituação transcendental (embora insistentemente secular): 'A lua era como o úbere de uma vaca', lemos em um ponto, 'se você puxasse suas tetas, teríamos sido cobertos por raios 
de luar' (p. 267). Em outro lugar, no capítulo intitulado "Choro", encontramos o seguinte:

Como a mãe não precisava perguntar nada, ela chorou muito e tudo ficou claro para ela. Mas é assim que as coisas são no mundo, para uma mulher, o choro está aí para ajudar quando a razão para de entender. E o choro sabe tudo, as palavras não sabem, os pensamentos não sabem, os sonhos não sabem, e às vezes o próprio Deus não sabe, mas o choro humano sabe. Porque chorar é chorar, e também é a coisa pela qual se chora (p. 309).

A atenção dos leitores foi compreensivelmente atraída para as páginas finais do romance, nas quais Szymek se dirige a Michał, compartilhando seus pensamentos mais profundos com ele, implorando-lhe para falar novamente para que possam enfrentar juntos a experiência de envelhecer e talvez recuperar a intimidade que uma vez sentiram, como irmãos. Digo "compreensivelmente", porque essas estão entre as páginas mais profundas e comoventes de Stone upon Stone. É para o assunto da linguagem que Szymek se volta aqui, lançando-a como o meio principal pelo qual nos tornamos humanos. Mas então ele supõe que a linguagem é também o que nos conecta, não apenas para aqueles que compartilham a terra conosco, mas para aqueles que foram antes de nós e aqueles que ainda vi- 
rão. E é o que une matéria e espírito, terra e esperança. 'O mundo inteiro é um grande idioma', diz ele.

Se você realmente ouvir com atenção, poderá até ouvir o que eles diziam há um século, talvez até milhares de anos atrás. Porque as palavras não conhecem a morte. Eles são como pássaros transparentes, uma vez que falam, elas circulam em torno de nós para sempre, só que não os ouvimos... A vida começa com uma palavra e termina com palavras. Porque a morte também é apenas o fim das palavras. Comece talvez com os primeiros disponíveis, aqueles que estão mais próximos de você. Mãe, casa, terra. Talvez tente dizer, terra. Quer dizer, você sabe o que é a terra. Onde você cospe? Na Terra. Você sabe, o que você anda, quais casas são construídas, o que você ara?... Eles dizem que quando uma pessoa nasce, a terra é seu berço. E tudo que a morte faz é colocar você de volta nela. E isso balança você e balança até que você seja, mais uma vez, não nascido, não seja concebido (p. 533-534).

Se essas linhas oferecem consolo, só pode ser no sentido adorniano: 'não há mais beleza do consolo, exceto no olhar caindo sobre o horror, resistindo a ele, e na consciência não aliviada da negatividade agarrando-se à possibilidade do que é melhor' (Adorno, p. 25). As palavras de Szymek vão para a frente e 
para trás, construindo um elo entre a extinção que é o destino de cada um de nós e a eternidade do esforço humano. Inconcepção, em um nível; um novo começo em outro. Molas surgindo da terra, o suor das pessoas escorrendo de volta para ela. Cinzas em cinzas, pó em pó: é assim que a vida de qualquer indivíduo pode ser resumida; mas não é assim que La Comédie humaine pode ser narrada. Para isso, você precisa dos noventa livros de Balzac; ou talvez apenas este de Myśliwski.

\section{Referências}

ACHEBE, Chinua. 'Colonialist Criticism'. Morning Yet on Creation Day: Essays. London: Heinemann, 1977, p. 3-18.

ACHEBE, Chinua. 'Africa and Her Writers'. Morning Yet on Creation Day: Essays. London: Heinemann, 1977, p. 19-29.

ADORNO, Theodor W. Minima Moralia: Reflections from Damaged Life [1951]. Trans. E.F.N.

Jephcott. London and New York: Verso, 1985.

AID00, Ama Ata. No Sweetness Here and Other Stories. London: Longman, 1970.

AID00, Ama Ata. 'To Be an African Woman Writer an Overview and a Detail'. Criticism andIdeology: Second African Writers' Conference, Stockholm 1986. Ed. Kirsten Holst Petersen. Uppsala: Scandinavian Institute of African Studies, 1988, p. 155-172. 
ARMAH, Ayi Kwei. The Beautyful Ones Are Not Yet Born [1968]. London: Heinemann, 1988.

AUSTER, Paul. 'The Art of Hunger' [1970]. The Art of Hunger: Essays, Prefaces, Interviews. Rev. edn. London: Penguin, 1997, p. 9-20.

BAHKTIN, M.M. and P.N. Medvedev. The Formal Method in Literary Scholarship: A Critical Introduction to Sociological Poetics [1928]. Trans. Albert J. Wehrle. Cambridge: Harvard University Press, 1985.

BERGER, John. Into Their Labours. New York: Pantheon, 1991. (Comprising Pig Earth, 1979, Once in Europa, 1887, and Lilac and Flag, 1990).

BERGER, John. Pig Earth. New York: Pantheon Books, 1979.

BERMAN, Marshall. All That Is Solid Melts Into Air: The Experience of Modernity. London: Verso, 1983. BHATTACHARYA, Bhabani. So Many Hungers! [1947]. Bombay: Jaico Publishing House, 1964.

CALHOUN, Craig, ed. Dictionary of the Social Sciences. Oxford: Oxford University Press, 2002.

CARTER, Martin. 'University of Hunger' [1954]. Poems by Martin Carter. Eds. Stewart Brown and Ian McDonald. Oxford: Macmillan Education, 2006, p. 18-20.

CHEKHOV, Anton. Anton Chekhov's Short Stories. Sel. \& ed. Ralph E. Matlaw. London and New York: W.W. Norton and Company, 1979. 
DICKENS, Charles. Dombey and Son [1844-1846]. London: Penguin Books, 1985.

DYER, Christopher. 'Work Ethics in the Fourteenth Century'. The Problem of Labour in Fourteenth-Century England. Ed. James Bothwell, P.J.P. Goldberg and W.M. Ormrod. York: York Medieval Press, 2000, p. 21-41.

EL-BISATIE, Mohamed. Hunger: An Egyptian Novel [2008]. Trans. Denys Johnson-Davies. Cairo: American University in Cairo Press, 2014.

ESTY, Joshua. 'Excremental Postcolonialism'. Contemporary Literature 40, 1999, p. 22-59.

Ferguson, Robert. Enigma: The Life of Knut Hamsun. London: Hutchinson, 1987.

FREUD, Sigmund. Civilization and Its Discontents [1930]. Trans. James Strachey. London and New York: W.W. Norton \& Company, 1961.

GAKOU, Mohamed Lamine. The Crisis in African Agriculture. London: Zed Books, 1987.

HAMSUN, Knut. Hunger [1890]. Trans. Robert Bly. London: Picador, 1974.

JAMESON, Fredric. 'Third-World Literature in the Era of Multinational Capitalism'. Social Text 15, p. 65-88. JAMESON, Fredric. Postmodernism or, The Cultural Logic of Late Capitalism. Durham: Duke University Press, 1995. 
KANG KYŎNG-AE. From Wonso Pond [1934]. Trans. Samuel Perry. New York: The Feminist Press at the City University of New York, 2009.

KAYE, Harvey J. 'A Question of History: John Berger's Labours'. Journal of Historical Sociology 1.4 (1988), p. 438-53.

KHLEBNIKOV, Velimir. 'Hunger' [1921]. Collected Works of Velimir Khlebnikov. Vol. III: Selected Poems. Trans. Paul Schmidt. Ed. Ronald Vroon. Cambridge: Harvard University Press, 1997, p. 104-110.

LAO SHE, Rickshaw [1937]. Trans. Jean M. James. Honolulu: University Press of Hawaii, 1979.

LAZARUS, Neil. Resistance in Postcolonial African Fiction. New Haven: Yale University Press, 1990

LIU ZHENYUN, Remembering 1942 and other Chinese Stories. Trans. Howard Goldblatt and Sylvia Li-chun Lin. New York: Arcade, 2016.

LONSDALE, John. 'Have Tropical Africa's Nationalisms Continued Imperialism's World Revolution by Other Means?' Nations and Nationalism 21.4 (2015), p. 609-629.

LUTZ, John. 'Pessimism, Autonomy, and Commodity Fetishism in Ayi Kwei Armah's The Beautyful Ones Are Not Yet Born'. Research in African Literatures 34.2, 2003, p. 94-111.

MAKHULU, Anne-Maria B. 'Introduction: Reckoning with Apartheid: The Conundrum of Working throu- 
gh the Past'. Comparative Studies of South Asia, Africa and the Middle East 36.2, 2016, p. 256-262.

MARECHERA, Dambudzo. The House of Hunger [1978]. Long Grove, IL: Waveland Press, 2013.

MARKANDAYA, Kamala. Nectar in a Sieve [1954]. New York: Penguin, 2007.

MARX, Karl; ENGELS Friedrich. Manifesto of the Communist Party [1848]. Beijing: Foreign Languages Press, 1988.

MISTRY, Rohinton. A Fine Balance [1995]. New York: Vintage International, 1997.

MOORE, Jason W. 'Amsterdam is Standing on Norway': Part I: 'The Alchemy of Capital, Empire and Nature in the Diaspora of Silver, 1545-1648'. Journal of Agrarian Change 10.1 (2010), p. 33-68; Part II: 'The Global North Atlantic in the Ecological Revolution of the Long Seventeenth Century'. Journal of Agrarian Change 10.2 (2010), p. 188-227.

MORETTI, Franco. 'Conjectures on World Literature'. New Left Review 1 (2000), p. 54-68. MYŚLIWSKI, Wiesław. Stone upon Stone [1999]. Trans. Bill Johnston. New York: Archipelago Books, 2010. MYŚLIWSKI, Wiesław. A Treatise on Shelling Beans [2006]. Trans. Bill Johnston. Brooklyn: Archipelago Books, 2013.

O'FLAHERTY, Liam. Famine [1937]. London: Merlin, 2004. 
OLLIKAINEN, Aki. White Hunger [2012]. Trans. Emily Jeremiah and Fleur Jeremiah. London: Peirene Press, 2015. PATON, Alan. Cry the Beloved Country. New York: Charles Scribner's Sons, 1948.

RÉE, Jonathan. Proletarian Philosophers: Problems in Socialist Culture in Britain 1900-1940.

Oxford, Oxford University Press, 1984.

SCHMITT-Kilb, Christian. 'A Huge Lacuna vis-à-vis the Peasants: Red and Green in John Berger's Trilogy Into Their Labours'. Ecology and the Literature of the British Left: The Red and the Green. Eds. John Rignall and H. Gustav Klaus, with Valentine Cunningham. London and New York: Routledge, 2016, p. 207-20.

TORRES, Antônio. The Land [1976]. Trans. Margaret A. Neves. London: Readers International, 1987.

TURGENEV, Ivan. 'Tatyana Borisovna and her Nephew'. Sketches from a Hunter's Album. Trans. Richard Freeborn. London: Penguin, 1990, p. 204-216. TURGENEV, Ivan. Fathers and Sons [1862]. Trans. Richard Freeborn. Oxford: Oxford University Press, 1998. WARWICK RESEARCH COLLECTIVE (WReC). Combined and Uneven Development: Towards a New Theory of World-Literature. Liverpool: Liverpool University Press, 2015. WIENTZEN, Timothy. 'The Aesthetics of Hunger: Knut Hamsun, Modernism, and Starvation's Global Frame'. Novel: A Forum on Fiction 48.2, 2015, p. 208-223. WILLIAMS, Raymond. The Country and the City. New York: Oxford University Press, 1973. 